\title{
Enhanced sensitivity to ethanol-induced inhibition of LTP in CA1 pyramidal neurons of socially isolated C57BL/6J mice: role of neurosteroids
}

\author{
Giuseppe Talani $^{1}{ }^{*}$, Giovanni Biggio $^{1,2}$ and Enrico Sanna ${ }^{1,2}$ \\ Section of Neuroscience, Department of Experimental Biology, Center of Excellence for the Neurobiology of Dependence, University of Cagliari, Monserrato, \\ Cagliari, Italy \\ 2 Institute of Neuroscience, National Research Council of Italy, Monserrato, Cagliari, Italy
}

\section{Edited by:}

Hubert Vaudry, University of Rouen,

France

Reviewed by:

Gustavo M. Somoza, Instituto de Investigaciones

Biotecnologicas - Instituto

Tecnologico de Chascomus, Argentina

Charles Zorumski, Washington

University, USA

${ }^{*}$ Correspondence:

Giuseppe Talani, Department of Experimental Biology, University of Cagliari, Cittadella Universitaria di

Monserrato, Cagliari 09042, Italy e-mail: giuseppetalani@yahoo.it
Ethanol (EtOH) induced impairment of long-term potentiation (LTP) in the rat hippocampus is prevented by the $5 \alpha$-reductase inhibitor finasteride, suggesting that this effect of EtOH is dependent on the increased local release of neurosteroids such as $3 \alpha, 5 \alpha-$ THP that promote GABA-mediated transmission. Given that social isolation (SI) in rodents is associated with altered plasma and brain levels of such neurosteroids as well as with an enhanced neurosteroidogenic action of $\mathrm{EtOH}$, we examined whether the inhibitory effect of $\mathrm{EtOH}$ on LTP at CA3-CA1 hippocampal excitatory synapses is altered in C57BL/6J mice subjected to $\mathrm{SI}$ for 6 weeks in comparison with group-housed (GH) animals. Extracellular recording of field excitatory postsynaptic potentials (fEPSPs) as well as patch-clamp analysis were performed in hippocampal slices prepared from both SI and GH mice. Consistent with previous observations, recording of fEPSPs revealed that the extent of LTP induced in the $\mathrm{CA} 1$ region of $\mathrm{SI}$ mice was significantly reduced compared with that in $\mathrm{GH}$ animals. $\mathrm{EtOH}$ $(40 \mathrm{mM})$ inhibited LTP in slices from SI mice but not in those from GH mice, and this effect of EtOH was abolished by co-application of $1 \mu \mathrm{M}$ finasteride. Current-clamp analysis of CA1 pyramidal neurons revealed a decrease in action potential (AP) frequency and an increase in the intensity of injected current required to evoke the first AP in SI mice compared with $\mathrm{GH}$ mice, indicative of a decrease in neuronal excitability associated with SI. Together, our data suggest that SI results in reduced levels of neuronal excitability and synaptic plasticity in the hippocampus. Furthermore, the increased sensitivity to the neurosteroidogenic effect of $\mathrm{EtOH}$ associated with $\mathrm{SI}$ likely accounts for the greater inhibitory effect of EtOH on LTP in SI mice. The increase in EtOH sensitivity induced by SI may be important for the changes in the effects of EtOH on anxiety and on learning and memory associated with the prolonged stress attributable to SI.

Keywords: social isolation, ethanol, hippocampus, neurosteroids, neuronal excitability, stress, LTP

\section{INTRODUCTION}

Ethanol (EtOH) influences the function of inhibitory $\gamma$ aminobutyric acid (GABA) type A receptors $\left(\mathrm{GABA}_{\mathrm{A}} \mathrm{Rs}\right)$ by various direct and indirect mechanisms (Criswell and Breese, 2005; Breese et al., 2006; Weiner and Valenzuela, 2006; Kumar et al., 2009; Kelm et al., 2011). EtOH thus selectively enhances the function of recombinant $\mathrm{GABA}_{\mathrm{A}}$ Rs containing $\alpha 4$ or $\alpha 6$ as well as $\delta$ subunits expressed in Xenopus laevis oocytes (SundstromPoromaa et al., 2002; Wallner et al., 2003) as well as tonic currents mediated by $\mathrm{GABA}_{\mathrm{A}}$ Rs containing $\alpha 4$ and $\delta$ subunits in hippocampal and thalamic slices in vitro (Hanchar et al., 2004; Wei et al., 2004; Glykys et al., 2007; Jia et al., 2007, 2008; Santhakumar et al., 2007). Indirect modulation of $\mathrm{GABA}_{\mathrm{A}} \mathrm{Rs}$ by $\mathrm{EtOH}$ has been shown to be mediated both presynaptically, through an increase in the probability of GABA release (Roberto et al., 2003; Carta et al., 2004; Sanna et al., 2004; Zhu and Lovinger, 2006), and postsynaptically, through stimulation of the biosynthesis of neuroactive steroids (Barbaccia et al., 1999; Morrow et al.,
1999, 2001; VanDoren et al., 2000; Sanna et al., 2004; Kumar et al., 2009).

Neuroactive steroids such as $3 \alpha, 5 \alpha$-tetrahydroprogesterone ( $3 \alpha, 5 \alpha$-THP, also known as allopregnanolone) and $3 \alpha, 5 \alpha-$ tetrahydrodeoxycorticosterone $(3 \alpha, 5 \alpha$-THDOC) are reduced metabolites of progesterone that rapidly alter neuronal excitability both by acting as potent positive modulators of $\mathrm{GABA}_{\mathrm{A}} \mathrm{Rs}$, especially those that contain the $\alpha 4$ and $\delta$ subunits and are located at extrasynaptic sites, as well as by influencing other neurotransmission systems (Rupprecht and Holsboer, 1999; Lambert et al., 2009). These steroids are produced by peripheral organs including the adrenal glands and gonads (Paul and Purdy, 1992), but they are also synthesized de novo in brain cells from cholesterol, in which case they are also referred to as neurosteroids (Hu et al., 1987; Mathur et al., 1993). $3 \alpha, 5 \alpha$-THP potentiates $\mathrm{GABA}_{\mathrm{A}} \mathrm{R}$-mediated responses in vitro at nanomolar concentrations, a potency greater than that of benzodiazepines or barbiturates (Majewska et al., 1986; Morrow et al., 1987, 1990; Reddy et al., 2004), and it exerts 
anxiolytic and sedative effects in vivo (Bitran et al., 1993, 1995; Freeman et al., 1993; Picazo and Fernandez-Guasti, 1995; Kokate et al., 1999; Reddy et al., 2004). Plasma and brain levels of GABAergic neuroactive steroids are affected by acute or chronic stress as well as by the acute administration of EtOH in rodents (Purdy et al., 1991; Concas et al., 1996; Barbaccia et al., 1999; Morrow et al., 1999; Serra et al., 2006).

The steroidogenic action of $\mathrm{EtOH}$ is thought to be mediated by stimulation of the hypothalamic-pituitary-adrenal (HPA) axis and results in an increase in the circulating and brain levels of neuroactive steroids. However, EtOH directly stimulates neurosteroidogenesis in rat brain slices and thus independently of peripheral organs (Sanna et al., 2004; Criswell and Breese, 2005; Izumi et al., 2007). EtOH induces the local release of neurosteroids at the synaptic level as well as positive modulation of $\mathrm{GABA}_{\mathrm{A}} \mathrm{Rs}$ in CA1 pyramidal neurons, with both effects being prevented by the $5 \alpha$ reductase inhibitor finasteride, suggesting that local production of neurosteroids such as $3 \alpha, 5 \alpha$-THP is necessary for modulation of $\mathrm{GABA}_{\mathrm{A}} \mathrm{R}$ function by EtOH. In addition, this neurosteroidogenic effect of EtOH was shown to result in inhibition of long-term potentiation (LTP) in the CA1 hippocampal region (Izumi et al., 2007). LTP in the hippocampus is a form of synaptic plasticity that provides a consolidated cellular mechanism of memory formation (Mayford, 2007). Membrane excitability in CA1 pyramidal neurons has been found to be related both to the performance of learning tasks (Moyer et al., 2000; Tombaugh et al., 2005) as well as to successful learning (Moyer et al., 1996; Thompson et al., 1996).

Postweaning social isolation (SI) is a well-characterized paradigm of mild prolonged stress that is associated with marked behavioral, neuroendocrine, and neurochemical changes (Hall et al., 1998; Serra et al., 2000, 2005, 2006; Ferdman et al., 2007) and that is dependent on gender (Pietropaolo et al., 2008). A decrease in the brain concentrations of GABAergic neuroactive steroids such as $3 \alpha, 5 \alpha-$ THP in animals subjected to SI is accompanied by an increased efficacy of EtOH in the stimulation of steroidogenesis and $\mathrm{GABA}_{\mathrm{A}} \mathrm{R}$ function (Serra et al., 2003, 2006). Moreover, SI induces increased voluntary consumption of EtOH in adult C57BL/6J mice (Sanna et al., 2011).

We have now evaluated the effects of SI on neuronal excitability and on the inhibition by EtOH of LTP induction in the CA1 region of the mouse hippocampus as well as the role of neurosteroids in such effects. The decrease in neurosteroid levels associated with SI was found to result in a reduced level of neuronal excitability and an enhanced inhibitory effect of EtOH on LTP in the CA1 hippocampal region.

\section{MATERIALS AND METHODS ANIMALS}

C57BL/6J mice (Charles River, Como, Italy) were bred in our animal facility and maintained under an artificial 12-h-light, 12h-dark cycle (lights on from 08:00 to 20:00 h), a constant temperature of $22 \pm 2^{\circ} \mathrm{C}$, and a relative humidity of $65 \%$. They had free access to water and standard laboratory food at all time. Animal care and handling throughout the experimental procedures were in accordance with the European Communities Council Directive of November 24, 1986 (86/609/EEC). The experimental protocols were also approved by the Animal Ethics Committee of the University of Cagliari.

\section{SI STRESS PARADIGM}

Newborn mouse pups were left undisturbed with their mothers until weaning ( 21 days). After weaning, male mice were randomly assigned to be housed six per cage (group-housed, GH) or one per cage (SI) for 6 weeks. In a separate set of experiments, 12 SI mice were injected once a day subcutaneously with progesterone $(5 \mathrm{mg} / \mathrm{kg}$, dissolved in $20 \% \beta$-cyclodextrin), and six of which were co-treated with finasteride $(25 \mathrm{mg} / \mathrm{kg}$, dissolved in $20 \%$ $\beta$-cyclodextrin, s.c.) throughout the entire 6-week period of isolation; control SI mice received an equivalent injection of the vehicle solution according to the same schedule.

\section{PREPARATION OF MOUSE HIPPOCAMPAL SLICES}

Hippocampal slices were prepared from GH and SI mice as previously described (Sanna et al., 2011). In brief, the animals were subjected to deep anesthesia with chloroform and decapitated, and the brain was rapidly removed from the skull. For extracellular recordings, the brain was transferred to a standard artificial cerebrospinal fluid (ACSF) containing (in mM): $126 \mathrm{NaCl}, 3 \mathrm{KCl}$, $2 \mathrm{CaCl}_{2}, 1 \mathrm{MgCl}_{2}, 26 \mathrm{NaHCO}_{3}, 1.25 \mathrm{NaH}_{2} \mathrm{PO}_{4}$, and $10 \mathrm{D}$-glucose ( $\mathrm{pH} 7.4$, set by aeration with $95 \% \mathrm{O}_{2}$ and $5 \% \mathrm{CO}_{2}$ ). Alternatively, for patch-clamp experiments, the brain was transferred to a modified ACSF containing (in $\mathrm{mM}$ ): 220 sucrose, $2 \mathrm{KCl}, 0.2 \mathrm{CaCl}_{2}, 6$ $\mathrm{MgSO}_{4}, 26 \mathrm{NaHCO}_{3}, 1.3 \mathrm{NaH}_{2} \mathrm{PO}_{4}$, and 10 D-glucose (pH 7.4, set by aeration with $95 \% \mathrm{O}_{2}$ and $5 \% \mathrm{CO}_{2}$ ). Coronal brain slices (thickness of 300 or $400 \mu \mathrm{m}$ ) containing the hippocampus were cut in ice-cold standard or modified ACSF with the use of a Leica VT1200S vibratome (Leica, Heidelberg, Germany). The slices were then transferred immediately to a nylon net submerged in standard ACSF for at least $40 \mathrm{~min}$ at a controlled temperature of $35^{\circ} \mathrm{C}$ (for patch-clamp experiments) or at room temperature (for extracellular recordings). After subsequent incubation for at least $1 \mathrm{~h}$ at room temperature, hemi-slices were transferred to the recording chamber, which was perfused with standard ACSF at a constant flow rate of $\sim 2 \mathrm{ml} / \mathrm{min}$. For all recordings, the temperature of the bath was maintained at $33^{\circ} \mathrm{C}$.

\section{EXTRACELLULAR RECORDING OF fEPSPS}

Recordings of field excitatory postsynaptic potentials (fEPSPs) were obtained from the stratum radiatum of the CA1 region of the hippocampus after stimulation of the Schaffer collateral afferents. Extracellular recording electrodes were prepared from borosilicate capillaries with an internal filament and an outer diameter of $1.5 \mu \mathrm{m}$ (Sutter Instruments, Novato, CA, USA) and were filled with $4 \mathrm{M} \mathrm{NaCl}$ (resistance, 1-2 M $\Omega$ ). For stimulation of afferents, a concentric bipolar electrode (FHC, Bowdoin, ME, USA) was positioned $\sim 300 \mu \mathrm{m}$ from the recording site. Responses were triggered digitally every $20 \mathrm{~s}$ with the use of an interval generator (Master $8, \mathrm{FHC}$ ) and a stimulus isolator by application of a constant current pulse of $0.2-0.4 \mathrm{~mA}$ with a duration of $60 \mu \mathrm{s}$, which yielded a half-maximal response. For determination of the input-output (I-O) relation, the stimulation current was adjusted from 0 to $1 \mathrm{~mA}$ in steps of $0.1 \mathrm{~mA}$. The fEPSPs were amplified with the use of an Axoclamp 2B amplifier (Axon Instruments, Union City, CA, 
USA), digitized, and then analyzed with Clampfit 9.02 software (Axon Instruments). Several kinetic parameters of fEPSPs were analyzed, but the slope values were considered for quantitation of the responses. For elicitation of LTP, after $10 \mathrm{~min}$ of stable baseline recording of fEPSPs evoked every $20 \mathrm{~s}$ at the current intensity that triggered $50 \%$ of the maximal fEPSP response, high-frequency stimulation (HFS) consisting of a single train of 100 stimuli at $250 \mathrm{~Hz}$ was delivered and recording was then continued for $60 \mathrm{~min}$ with stimulation of fEPSPs every $20 \mathrm{~s}$.

\section{WHOLE-CELL PATCH-CLAMP RECORDINGS}

Whole-cell recordings from hippocampal CA1 pyramidal neurons were performed as previously described (Sanna et al., 2011). Recording pipettes were prepared from borosilicate glass with the use of a Flaming Brown micropipette puller (Molecular Devices, Novato, CA, USA). Resistance of the pipettes ranged from 2.5 to $4.5 \mathrm{M} \Omega$ when they were filled with an internal solution containing $135 \mathrm{mM}$ potassium gluconate, $10 \mathrm{mM} \mathrm{MgCl}_{2}$, $0.1 \mathrm{mM} \mathrm{CaCl}_{2}, 1 \mathrm{mM}$ EGTA, $10 \mathrm{mM}$ Hepes-KOH (pH 7.3), and $2 \mathrm{mM}$ ATP (disodium salt). We analyzed only recordings with access resistance of $<25 \mathrm{M} \Omega$ (values usually ranged from 9 to $20 \mathrm{M} \Omega$ ). Series resistance was not compensated, and cells were excluded from further analysis if access resistance changed by $>20 \%$ during the course of the recording. Membrane potentials were recorded with the use of an Axopatch 200-B amplifier (Axon Instruments), filtered at $2 \mathrm{kHz}$, and digitized at $5 \mathrm{kHz}$. For patch-clamp experiments, we used pClamp 9.2 software (Molecular Devices, Union City, CA, USA), which allowed us to measure various characteristics of the neuronal membrane and action potentials (APs). For current-clamp experiments, we applied a protocol with injected current steps of 400-ms duration and ranging in intensity from -80 to $200 \mathrm{pA}$ in intervals of $20 \mathrm{pA}$ in order to hyperpolarize or depolarize the membrane potential. The parameters analyzed included resting membrane potential, input resistance, AP threshold, minimum injected current capable of evoking the first AP, spike latency (time required for the first AP to occur in response to depolarization), and spike frequency. Input resistance was calculated from only the hyperpolarizing current steps.

\section{RECORDING OF SPONTANEOUS LOCOMOTOR ACTIVITY}

Group-housed and SI mice were tested at the end of the 6-week housing period. To determine general locomotor activity levels and exploration habits, we used a motility meter (Omnitech Electronics Inc.). Animals were left in the same room in which the apparatus was placed for at least $2 \mathrm{~h}$ before the beginning of experiments in order to allow their habituation to the environment. Individual mice were placed in the center of a square arena (20.3 by $20.3 \mathrm{~cm}$ ) and allowed to move freely for $60 \mathrm{~min}$ while being tracked by the automated tracking system. Parameters were monitored every $5 \mathrm{~min}$ (total of 12 acquisitions). Data obtained during the first $10 \mathrm{~min}$ were used for comparison among groups. The arena was assembled with specially designed sound-attenuating shells made of polypropylene and an expanded PVC sheet. The animals were isolated from noise of the recorder and printer used to acquire the data by placing these devices in a different room. The parameters measured included horizontal activity (number of photobeam interruptions), total distance traveled (centimeters), locomotion time (seconds), and rest time (seconds).

\section{STATISTICAL ANALYSIS}

Data are presented as means \pm SEM and were compared by oneway analysis of variance (ANOVA) or Student's $t$-test with the use of Prism software (version 5, GraphPad). A $p$ value of $<0.05$ was considered statistically significant.

\section{RESULTS \\ EFFECTS OF SI ON NEURONAL EXCITABILITY AND LTP INDUCTION IN THE HIPPOCAMPAL CA1 REGION OF C57BL/6J MICE}

To examine the effect of SI on neuronal excitability in the CA1 region of the mouse hippocampus, we generated I-O curves by stimulating the Schaffer collateral glutamatergic afferents with increasing (0-1.0 mA) current intensity and recorded fEPSPs from the dendritic region within the CA1 stratum radiatum. Consistent with previous observations (Bartesaghi, 2004; Sanna et al., 2011), the intensity of the stimulatory current that evoked a half-maximal response (quantified by analysis of the fEPSP slope) was significantly $(p<0.05)$ increased in hippocampal slices from SI mice $(0.45 \pm 0.02 \mathrm{~mA})$ compared with that for $\mathrm{GH}$ mice $(0.37 \pm 0.01 \mathrm{~mA}$; Figure 1A).

We then examined the effect of SI on LTP induction in the CA1 region. After a 10-min baseline recording was obtained by stimulation at the current intensity that elicited a half-maximal response and at a frequency of $0.05 \mathrm{~Hz}, \mathrm{LTP}$ was induced by HFS of the Schaffer collateral afferents with a single train of 100 stimuli of the same intensity and at $250 \mathrm{~Hz}$. Separate experiments in hippocampal slices obtained from GH mice revealed that the LTP induced with such stimulus frequency was dependent on $\mathrm{N}$ methyl-D-aspartate (NMDA) receptors, as bath perfusion of AP5 $(50 \mu \mathrm{M})$ completely prevented its induction, and it was not influenced by the L-type voltage-dependent $\mathrm{Ca}^{2+}$ channel antagonist nifedipine (10 $\mu \mathrm{M}$; Figure 1B). As expected (Sanna et al., 2011), the extent of LTP, calculated by averaging the slope values of fEPSPs recorded between 50 and 60 min after HFS, was significantly $(p<0.05)$ lower in slices from SI mice than in those from $\mathrm{GH}$ animals (Figures 1C,D). The effect of HFS on the I-O curves also differed between the two groups of animals. Indeed, at $60 \mathrm{~min}$ after HFS, the maximal response was enhanced to a greater extent in GH mice $(+167 \%)$ than in SI animals $(+60 \%$; Figures 1E,F). The current intensity that evoked a half-maximal response after HFS did not differ significantly between GH and SI animals (data not shown).

\section{ENHANCED SENSITIVITY OF SI ANIMALS TO THE INHIBITORY EFFECT OF EtOH ON LTP IN THE CA1 REGION}

Given that SI was previously shown to increase the sensitivity of rats to the steroidogenic effect of acute systemic administration of EtOH (Serra et al., 2006), we examined the effect of EtOH on LTP in hippocampal slices from both GH and SI mice. The concentration of EtOH studied $(40 \mathrm{mM})$ was selected as the highest level that had no effect on LTP in GH mice. EtOH ( $40 \mathrm{mM})$ was applied to hippocampal slices of both $\mathrm{GH}$ and SI mice $30 \mathrm{~min}$ before HFS and was found to significantly $(p<0.05)$ reduce (by $67 \%$ ) the extent of LTP in SI mice but not in GH animals 


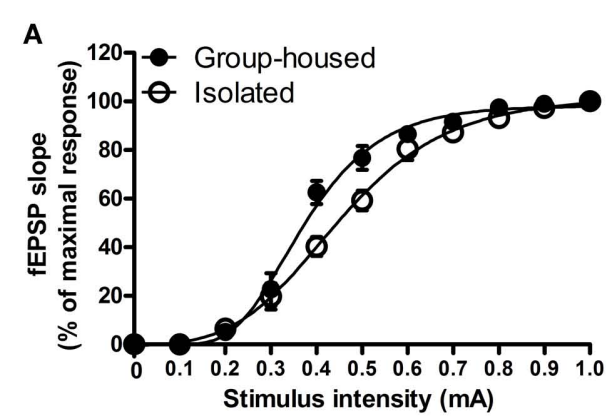

C
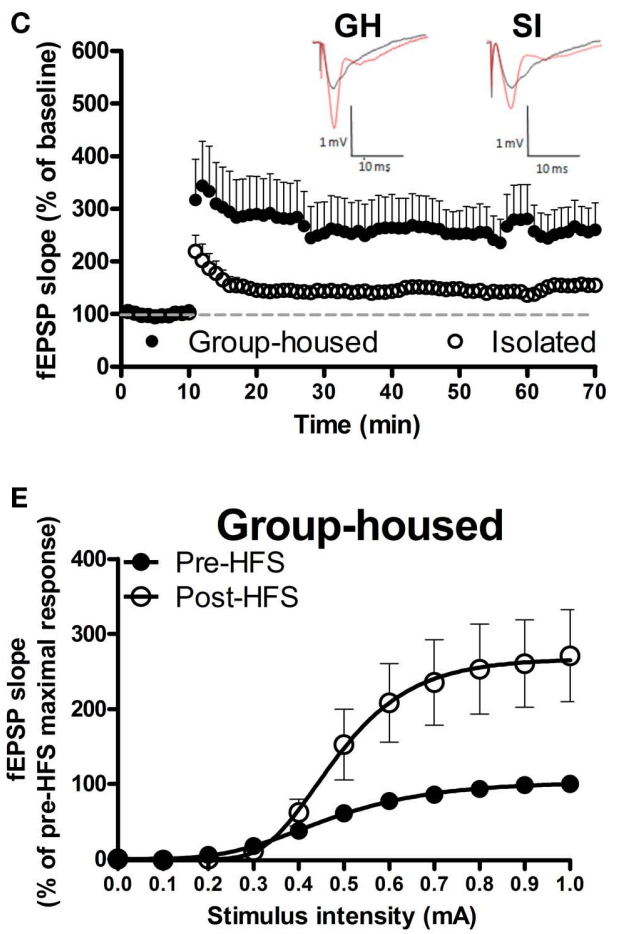

FIGURE 1 | Effects of social isolation on neuronal excitability and LTP induction in the hippocampus of C57BL/6J mice. Field excitatory postsynaptic potentials (fEPSPs) were recorded in the dendritic CA1 region of hippocampal slices obtained from group-housed (GH) or socially isolated (SI) animals. (A) Input-output (I-O) relations determined by measurement of fEPSP slope in response to stimulation of Schaffer collaterals with current of increasing intensity (from 0 to $1.0 \mathrm{~mA}$ ). Data are expressed as a percentage of the corresponding maximal response and are means \pm SEM $(n=12-20)$. (B) LTP induction calculated between 50 and 60 min after HFS stimulation is not affected by the voltage-dependent calcium channel antagonist nifedipine $(10 \mu \mathrm{M})$, but it is completely prevented by the perfusion (before and after
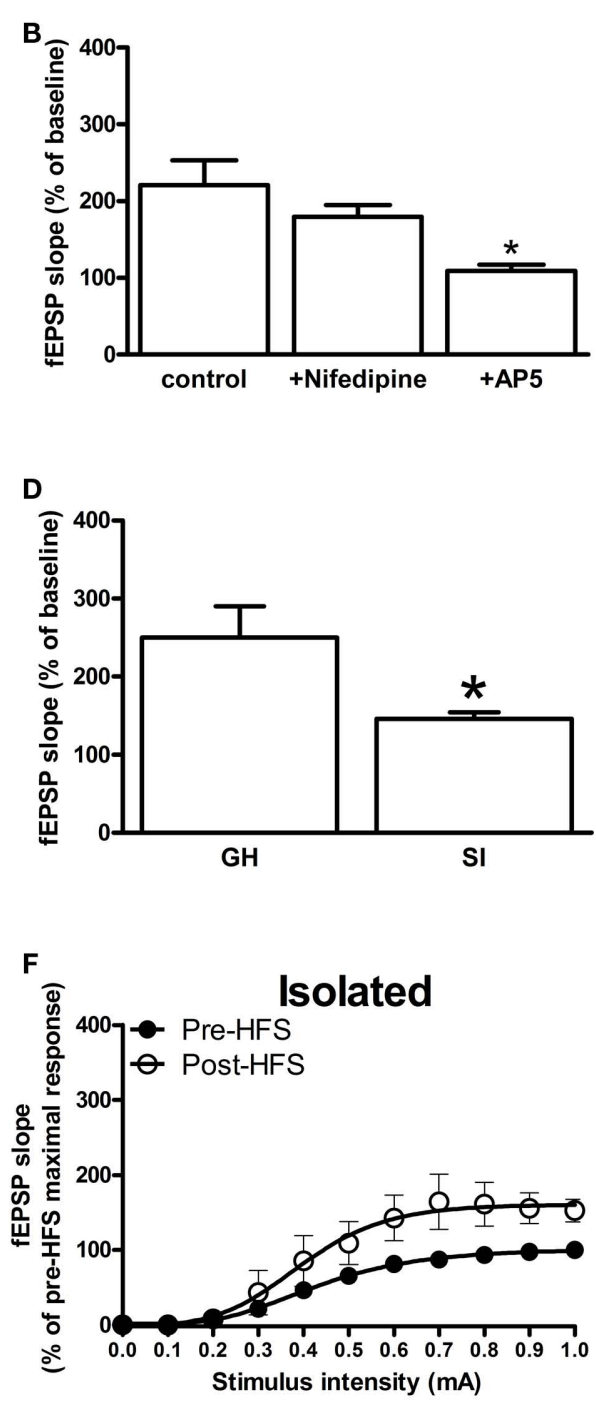

HFS) of the NMDA receptor antagonist AP5 $(50 \mu \mathrm{M})$. (C) LTP was induced in the CA1 region by HFS (arrow) of the Schaffer collateral-CA1 pathway. Data represent $f E P S P$ slope at the indicated times expressed as a percentage of that at baseline and are means \pm SEM ( $n=8-12$ slices). Above the bar graph, representative traces of fEPSPs obtained from GH and SI mice before (black trace) and 50 min after (red trace) high-frequency stimulation (HFS). (D) The extent of LTP was calculated by averaging the change in fEPSP slope apparent between 50 and 60 min after HFS. Data are means \pm SEM ( $n=8-12$ slices). ${ }^{*} p<0.05$ vs. GH mice. (E,F) $\mathrm{I}-\mathrm{O}$ relations before and $60 \mathrm{~min}$ after HFS in $\mathrm{GH}$ (E) and SI (F) mice. Data are expressed as a percentage of the maximal response measured before HFS and are means \pm SEM ( $n=8-12$ slices).
(Figures 2A-C,E-G). The ability of EtOH to inhibit LTP in the hippocampal CA1 region was previously shown to be dependent on stimulation of the local biosynthesis and release of $5 \alpha$-reduced pregnane neurosteroids such as $3 \alpha, 5 \alpha$-THP (Izumi et al., 2007). To test whether such a mechanism was also operative under our experimental conditions, we examined the effect of finasteride, an inhibitor of $5 \alpha$-reductase (Finn et al., 2006) that prevents the formation of GABAergic neurosteroids (Sanna et al., 2004). The coapplication of EtOH $(40 \mathrm{mM})$ and finasteride $(1 \mu \mathrm{M})$ prevented the inhibitory effect of EtOH on LTP in hippocampal slices from SI mice, but it had no effect on LTP in those from GH animals (Figures 2A-C,E-G). In addition, finasteride application did not alter basal LTP when measured in slices from either GH or SI mice (results not shown).

Evaluation of the I-O relations before and after HFS, either in the absence or presence of EtOH or finasteride, revealed that the maximal post-HFS response was markedly reduced by EtOH in SI mice, but not in GH mice, and that finasteride abolished this 
A

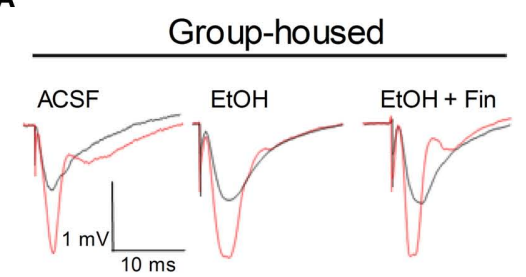

B

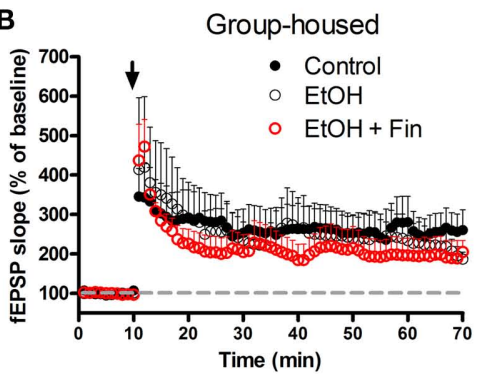

C
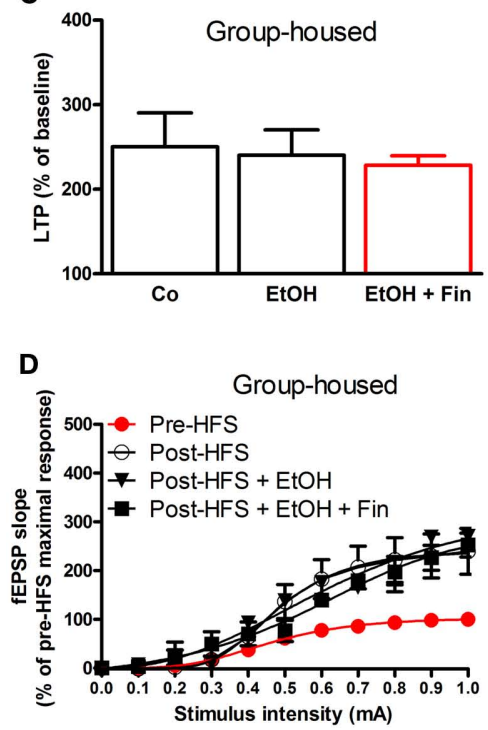

FIGURE 2 | Differential effects of EtOH and finasteride on LTP induction in the $\mathrm{CA} 1$ region of $\mathrm{SI}$ and $\mathrm{GH}$ mice. $(\mathrm{A}, \mathrm{E})$

Representative traces of fEPSPs obtained from hippocampal slices of GH (A) and SI (E) mice before (black trace) and 60 min after (red trace) $\mathrm{HFS}$ in the absence or presence of $\mathrm{EtOH}$ or finasteride (Fin). EtOH ( $40 \mathrm{mM}$ ) was applied to hippocampal slices $30 \mathrm{~min}$ before HFS, whereas finasteride $(1 \mu \mathrm{M})$ was applied $10 \mathrm{~min}$ before EtOH. (B,F) LTP was induced in the CA1 region of hippocampal slices from GH (B) and SI (F) mice by HFS (arrow) of the Schaffer collateral-CA1 pathway in the absence or presence of $\mathrm{EtOH}$ or
$\mathbf{E}$
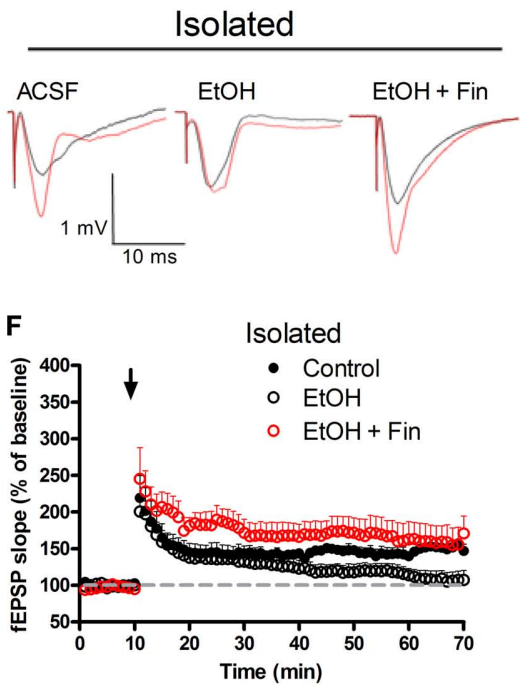

G
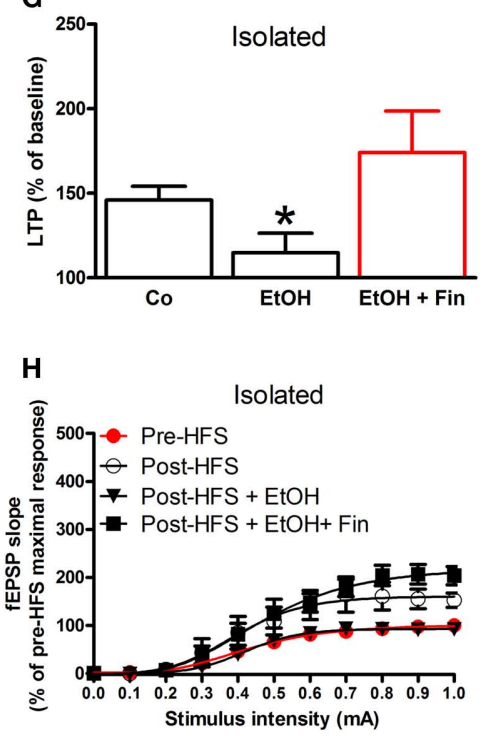

finasteride, as indicated. Data represent fEPSP slope at the indicated times expressed as a percentage of that at baseline and are means \pm SEM ( $n=5$ or 6 slices). (C,G) The extent of LTP was calculated by averaging the change in fEPSP slope apparent between 50 and 60 min after HFS in hippocampal slices from $\mathrm{GH}$ (C) and SI (G) mice. Data are means \pm SEM ( $n=5$ or 6 slices). ${ }^{*} p<0.05$ vs. control. (D,H) I-O relations determined before and $60 \mathrm{~min}$ after HFS in GH (D) and SI (H) mice. Data are expressed as a percentage of the maximal response measured before HFS and are means \pm SEM ( $n=8-12$ slices $)$ inhibitory effect of EtOH in slices from SI mice without having an effect in slices from GH animals (Figures 2D,H).

\section{EFFECTS OF SI ON MEMBRANE EXCITABILITY OF CA1 PYRAMIDAL NEURONS}

To evaluate further the effects of SI on CA1 neuronal excitability, we performed patch-clamp experiments in the current-clamp mode with single pyramidal neurons present in hippocampal slices of both $\mathrm{GH}$ and SI animals. The resting membrane potential was similar in SI $(-65.7 \pm 1.2 \mathrm{mV}, n=25$ cells $)$ and $\mathrm{GH}(-69.6 \pm 1.3 \mathrm{mV}, n=37)$ mice (Figure 3A). We measured the input resistance by injecting hyperpolarizing current pulses at various intensities and recording the relative negative deflections in membrane potential. Analysis of the voltage-current curves indicated that input resistance did not differ significantly between $\mathrm{GH}$ and SI mice $(\mathrm{GH}, 0.221 \pm 0.01 \mathrm{G} \Omega, n=37$; SI, $0.199 \pm 0.02 \mathrm{G} \Omega, n=25$; Figures 3B,C). Firing of APs was also analyzed by injection of depolarizing current pulses (Figure 3D). 
$A$ ริ

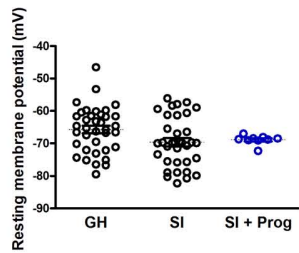

D Group-housed

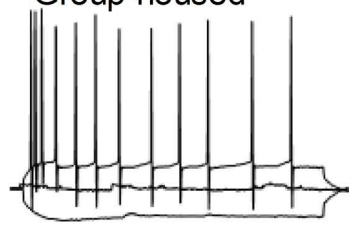

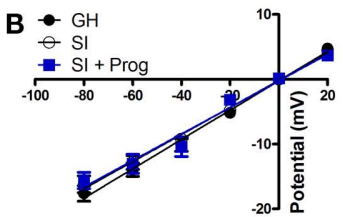

Current (pA)
C

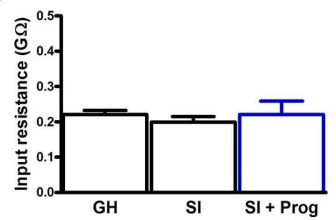

Isolated

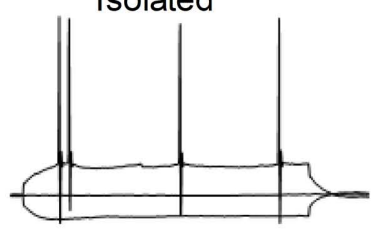

Isolated + Prog
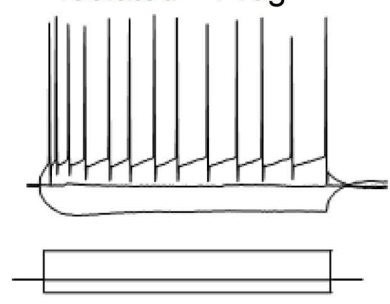

$\mathbf{F}$
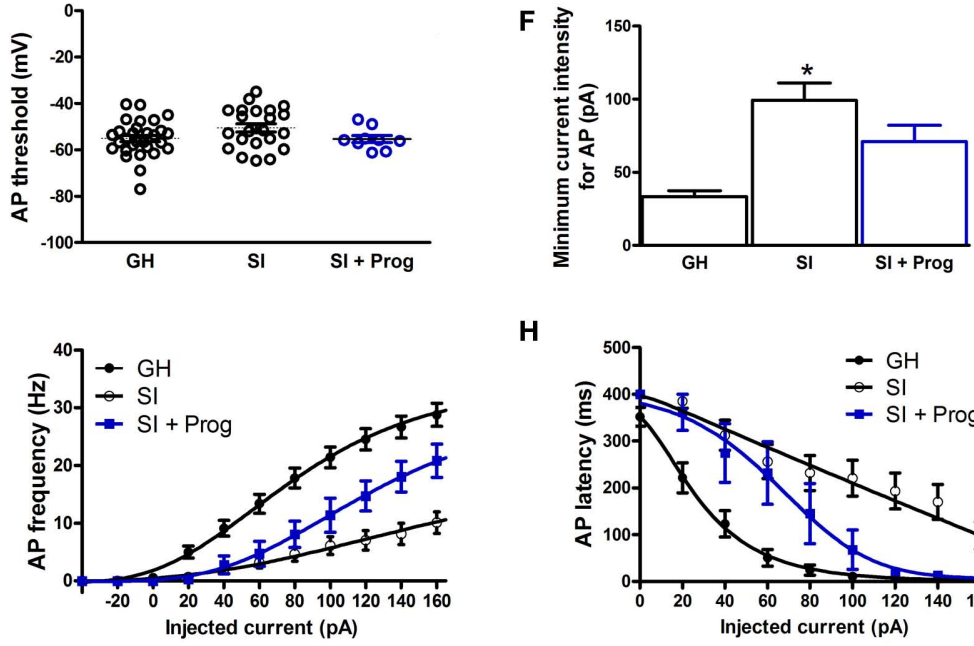

FIGURE 3 | Effects of SI on hippocampal CA1 pyramidal neuron excitability and their reversal by progesterone treatment. (A-C) Lack of effect of SI or progesterone (Prog) treatment on membrane resting potential $(\mathbf{A})$ the membrane potential-current relation (B) or membrane input resistance $\mathbf{( C )}$ determined by whole-cell patch-clamp analysis in the current-clamp mode. SI mice were treated daily with progesterone or vehicle before analysis. Data are for 37, 25, and 9 neurons in (A) and for 37,25 , and 9 neurons in $(\mathbf{B}, \mathbf{C})$ for $\mathrm{GH}, \mathrm{SI}$, and

progesterone-treated SI mice, respectively; those in $\mathbf{( B , C )}$ are means \pm SEM.

The threshold membrane potential for AP firing did not differ between the two groups of mice (Figure 3E). However, the minimum current intensity required for generation of an $\mathrm{AP}$ was significantly greater for CA1 pyramidal neurons of SI mice than for those of GH mice (Figure 3F). In addition, pyramidal neurons from SI mice were characterized by a reduced AP frequency (Figure 3G) and an increased AP latency (Figure 3H) compared with $\mathrm{GH}$ animals.

\section{EFFECTS OF PROGESTERONE TREATMENT ON SI-INDUCED CHANGES IN NEURONAL EXCITABILITY AND LTP}

Social isolation in rodents is associated with reduced plasma and brain levels of neuroactive steroids (Serra et al., 2000). We tested whether such an SI-induced decrease in neuroactive steroid levels

H

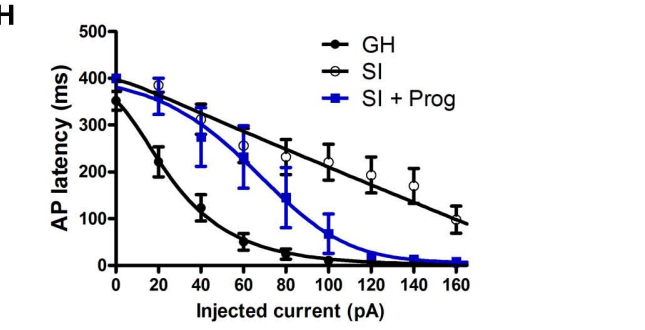

(D) Representative membrane voltage responses to negative ( $-20 \mathrm{pA})$ and positive $(+60 \mathrm{pA})$ current pulses applied to CA1 pyramidal neurons in hippocampal slices from GH or SI (with or without progesterone treatment) mice. (E-H) Effects of SI and progesterone treatment on the mean action potential (AP) threshold (E), minimum current intensity required for induction of the first AP (F), AP frequency at each depolarizing current step (G), and AP latency $\mathbf{( H )}$. Data are means \pm SEM for 37 neurons of $\mathrm{GH}$ mice, 25 neurons of SI mice, and 9 neurons of SI mice treated with progesterone. ${ }^{*} p<0.01$ vs. GH. might affect hippocampal neuronal excitability and synaptic plasticity. We thus treated a separate group of mice with progesterone $(5 \mathrm{mg} / \mathrm{kg}$, subcutaneous, once a day) during the entire 6-week period of SI (Figure 3). Progesterone treatment resulted in a partial reversal of the decrease in CA1 pyramidal neuron excitability apparent in SI mice, as reflected by the change in spike frequency (Figure 3G, $n=9$ ), spike latency (Figure 3H, $n=9$ ), and the minimum current required to evoke the first AP (Figure 3F, $n=9$ ). Progesterone treatment also partially reversed the reduction in the extent of LTP induced by SI (Figure 4); this effect is particularly evident for the late phase of LTP, while the early phase appears to be less influenced by such treatment. Furthermore, given that we recently showed that SI results in a decrease in spontaneous locomotor activity in mice subjected to the open field test (Sanna 
et al., 2011), we also evaluated the effect of progesterone treatment in this behavioral paradigm. Progesterone treatment reversed the SI-induced decreases in both horizontal activity and total distance traveled (Table 1). However, the changes in locomotion time and rest time induced by SI were not significantly affected by progesterone treatment. Finally, the effects of progesterone treatment in SI mice on LTP and spontaneous locomotor activity were abolished when measured in SI animals that were co-administered with progesterone and finasteride $(25 \mathrm{mg} / \mathrm{kg}$, s.c.; Figure 4 and Table 1).

\section{DISCUSSION}

We have found that rearing of mice in isolation for 6 weeks after weaning resulted in a decrease in the excitability of CA1 pyramidal neurons that was accompanied by a reduction in the extent of LTP induction as well as an enhanced inhibitory effect of EtOH on LTP as compared with control mice housed in groups. These

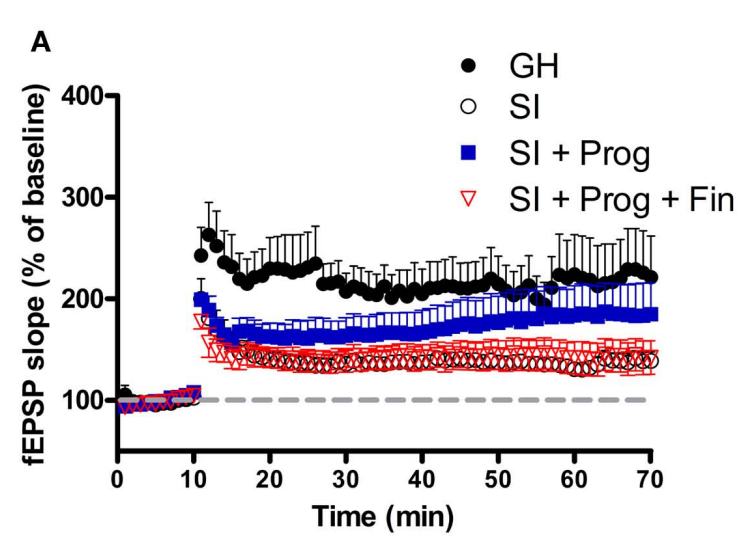

B

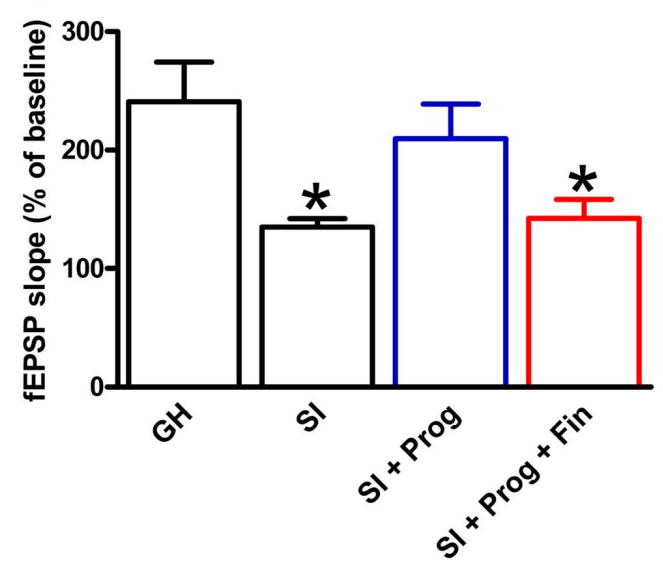

FIGURE 4 | Reversal of the effect of SI on LTP in the CA1 region by progesterone treatment: effect of the co-treatment with progesterone and finasteride. (A) LTP was induced in the CA1 region by HFS (arrow) of the Schaffer collateral-CA1 pathway in hippocampal slices obtained from GH mice as well as from SI mice that had been treated or not with progesterone. Data represent fEPSP slope at the indicated times expressed as a percentage of that at baseline and are means \pm SEM ( $n=6-10$ slices). (B) The extent of LTP was calculated by averaging the change in fEPSP slope apparent between 50 and 60 min after HFS. Data are means \pm SEM ( $n=6-10$ slices). ${ }^{*} p<0.05$ vs. GH mice. effects of SI on neuronal excitability and LTP appear to be related to the decrease in neuroactive steroid levels induced by this condition, given that they were reversed by treatment of mice with progesterone during the SI period.

Postweaning SI in C57BL/6J mice is studied as an animal model of prolonged mild stress and has been shown to be associated with marked changes in the activity of the HPA axis, increased sensitivity to the steroidogenic effect of $\mathrm{EtOH}$, and increased voluntary consumption of EtOH (Matsumoto et al., 1999; Serra et al., 2000, 2006; Sanna et al., 2011). We have now shown that SI-induced a marked decrease in neuronal excitability in CA1 pyramidal neurons of $\mathrm{C} 57 \mathrm{BL} / 6 \mathrm{~J}$ mice. Current-clamp recordings thus revealed different responses of neurons from $\mathrm{GH}$ or SI mice to depolarizing current pulses injected to trigger the firing of APs. CA1 neurons of SI mice needed higher current pulses to evoke the first AP, and they showed a lower AP frequency and increased spike latency. Neither resting membrane potential nor input resistance differed significantly between CA1 neurons from the two types of mice. These data are consistent with those of previous studies showing that SI is associated with pronounced changes in neuronal membrane excitability (Moyer et al., 1996, 2000; Thompson et al., 1996; Tombaugh et al., 2005). Extracellular recordings of fEPSPs in the hippocampal CA1 region of SI mice also revealed a reduced excitability at the Schaffer collateral-CA1 glutamatergic synapses, as revealed by a rightward shift in the I-O curve compared with that of $\mathrm{GH}$ mice. These results are also in agreement with those of a previous study of the guinea pig hippocampus (Bartesaghi, 2004).

As we suggested previously (Sanna et al., 2011), the reduced excitability of CA1 pyramidal neurons of SI mice might be responsible for the reduced level of LTP induced at Schaffer collateralCA1 synapses in these animals. Our present data are thus consistent with previous studies suggesting that long-term synaptic plasticity in several brain areas is markedly modified by the stress associated with SI (Roberts and Greene, 2003; Bianchi et al., 2006; Conrad et al., 2011).

We found that $\mathrm{EtOH}$ at $40 \mathrm{mM}$ inhibited the induction of LTP in the CA1 region of SI mice but not in that of GH mice, consistent with the enhanced sensitivity to this drug previously shown to be induced by SI. The inhibitory effect of EtOH on LTP was previously shown to be dependent on its stimulation of neurosteroidogenesis (Izumi et al., 2007). Co-application of the $5 \alpha$-reductase inhibitor finasteride was also previously shown to abolish the inhibitory effect of EtOH on $\mathrm{GABA}_{\mathrm{A}} \mathrm{R}$ function as well as neurosteroid synthesis in the brain (Sanna et al., 2004). Ethanol impairs LTP or other forms of synaptic plasticity in several brain regions including the hippocampus (Morrisett and Swartzwelder, 1993; Izumi et al., 2005), striatum (Yin et al., 2007), and cerebellum (Belmeguenai et al., 2008), but a role for neurosteroids in the EtOH induced impairment of LTP in the rat hippocampus was only recently proposed (Izumi et al., 2007). The reduced levels of hippocampal excitability and LTP observed in SI mice might explain the deficits in learning and memory induced by isolation in C57BL/6J mice (Voikar et al., 2005) as well as in rats (Lu et al., 2003; Bianchi et al., 2006; Quan et al., 2010). 
Table 1 | Changes in spontaneous locomotor activity in SI mice: effect of treatment with progesterone and co-treatment with progesterone and finasteride.

\begin{tabular}{lcccc}
\hline Parameter & Group-housed & Isolated & Isolated + progesterone & Isolated + progesterone + finasteride \\
\hline Horizontal activity & $1607 \pm 88.9$ & $1266 \pm 83.5^{*}$ & $1479 \pm 89.7$ & $1190 \pm 45.3^{*}$ \\
Total distance (cm) & $399.1 \pm 38.76$ & $256.9 \pm 27.2^{*}$ & $332.1 \pm 24.4$ & $231 \pm 20.5^{*}$ \\
Locomotion time (s) & $53.7 \pm 7.52$ & $34.3 \pm 4.6^{*}$ & $37.8 \pm 2.7^{*}$ & $35 \pm 5.9^{*}$ \\
Rest time (s) & $242.2 \pm 7.7$ & $265.5 \pm 7.3^{*}$ & $260.8 \pm 2.8^{*}$ & $261 \pm 6.0^{*}$
\end{tabular}

A group of SI mice were treated with progesterone $(5 \mathrm{mg} / \mathrm{kg}$, s.c.) or progesterone together with finasteride $(25 \mathrm{mg} / \mathrm{kg}$, s.c.) once a day for the 6-week isolation period. Data are means \pm SEM for six mice and were obtained during the first $10 \mathrm{~min}$ (of a total of $60 \mathrm{~min}$ ) of the experiment. ${ }^{*} p<0.05 \mathrm{vs}$. GH mice.

To examine whether the reduced brain levels of neurosteroids such as $3 \alpha, 5 \alpha$-THP and $3 \alpha, 5 \alpha$-THDOC associated with SI might be important for the changes in hippocampal excitability and in sensitivity to the steroidogenic effect of $\mathrm{EtOH}$ induced by isolation in mice, we administered progesterone daily during the 6-week period of isolation in an attempt to restore the normal levels of neuroactive steroids in the hippocampus (Costa et al., 1995; Moran et al., 1998). We found that such progesterone treatment during SI partially reversed the decreases in the levels of neuronal membrane excitability and LTP induced by SI. It should be noted that the protective effect of progesterone treatment on SI-induced decreased in LTP appears to be mostly involving the late phase of this phenomenon, whereas the early phase was less influenced (Figure 4); however, the reason for such differential action is at present unknown.

Progesterone treatment also attenuated the decrease in spontaneous locomotor activity shown to be induced by SI in previous studies (Valzelli et al., 1974; Voikar et al., 2005; Fone and Porkess, 2008; Pietropaolo et al., 2008; Arndt et al., 2009; Sanna et al., 2011). Furthermore, the effects of progesterone on LTP and spontaneous locomotor activity induced by SI were prevented by the concomitant administration of finasteride.

Social isolation is associated with increased expression of several subunits of GABA $\mathrm{G}_{\mathrm{A}}$, in particular $\delta$ and $\alpha 4$ subunits, in both rats (Serra et al., 2006) and mice (Sanna et al., 2011). Tonic inhibition is thought to play a key role in regulation of membrane excitability under both physiological and pathological conditions that have been shown to be associated with marked modulation of extrasynaptic $\mathrm{GABA}_{\mathrm{A}} \mathrm{R}$ function and subunit expression (Maguire et al., 2005; Serra et al., 2006; Maguire and Mody, 2008;
Sanna et al., 2009, 2011). We propose that the effects of SI on CA1 excitability and LTP are mediated in part by a decrease in excitability of granule cells in the dentate gyrus that results from an increase in GABAergic tonic current (Sanna et al., 2011) and which may lead to suppression of the activity of the entire dentate gyrus-CA3-CA1 circuitry. In line with this idea, Bartesaghi (2004) demonstrated that early isolation in guinea pigs results in a reduction in the synaptic function of the DG-CA3-CA1 neuronal circuitry. However, the impact of prolonged stress on hippocampal function may be more complex. In fact, Airan et al. (2007) working in the ventral hippocampal found that following chronic mild stress exposure in adult female rats there was diminished inflow through dentate, consistent with our results, but output from area CA1 was actually increased, resulting in an I-O mismatch.

Our present results provide new insight into changes in hippocampal function induced by SI in mice, including impairment of neuronal excitability and LTP associated with an increased sensitivity to the steroidogenic effect of moderate doses of EtOH. Furthermore, the increased sensitivity to the neurosteroidogenic effect of EtOH associated with SI likely accounts for the greater inhibitory effect of EtOH on LTP in SI mice. These effects of SI may be related to the deficits in learning and memory and changes in responses to $\mathrm{EtOH}$ that are associated with isolation, and they warrant further investigation with regard to the control of GABAergic transmission by neurosteroids at the level of the dentate gyrus.

\section{ACKNOWLEDGMENTS}

Funding for this study was provided by grant L.R. 7/2007 no. CRP3_63 from RAS (Regione Autonoma della Sardegna).

\section{REFERENCES}

Airan, R. D., Meltzer, L. A., Roy, M., Gong, Y., Chen, H., and Deisseroth, K. (2007). High-speed imaging reveals neurophysiological links to behavior in an animal model of depression. Science 317, 819-823.

Arndt, S. S., Laarakker, M. C., van Lith, H. A., van der Staay, F. J., Gieling, E., Salomons, A. R., van't Klooster, J., and Ohl, F. (2009). Individual housing of mice - impact on behaviour and stress responses. Physiol. Behav. 97, 385-393.

Barbaccia, M. L., Affricano, D., Trabucchi, M., Purdy, R. H., Colombo,
G., Agabio, R., and Gessa, G. L. (1999). Ethanol markedly increases "GABAergic" neurosteroids in alcohol-preferring rats. Eur. J. Pharmacol. 384, R1-R2.

Bartesaghi, R. (2004). Effect of early isolation on the synaptic function in the dentate gyrus and field CA of the guinea pig. Hippocampus 14, 482-498.

Belmeguenai, A., Botta, P., Weber, J. T., Carta, M., De Ruiter, M., De Zeeuw, C. I., Valenzuela, C. F., and Hansel, C. (2008). Alcohol impairs long-term depression at the cerebellar parallel
fiber-Purkinje cell synapse. J. Neurophysiol. 100, 3167-3174.

Bianchi, M., Fone, K. F., Azmi, N., Heidbreder, C. A., Hagan, J. J., and Marsden, C. A. (2006). Isolation rearing induces recognition memory deficits accompanied by cytoskeletal alterations in rat hippocampus. Eur. J. Neurosci. 24, 2894-2902.

Bitran, D., Purdy, R. H., and Kellogg, C. K. (1993). Anxiolytic effect of progesterone is associated with increases in cortical allopregnanolone and GABAA receptor function. Pharmacol. Biochem. Behav. 45, 423-428.
Bitran, D., Shiekh, M., and McLeod, M. (1995). Anxiolytic effect of progesterone is mediated by the neurosteroid allopregnanolone at brain GABAA receptors. J. Neuroendocrinol. 7, 171-177.

Breese, G. R., Criswell, H. E., Carta, M., Dodson, P. D., Hanchar, H. L., Khisti, R. T., Mameli, M., Ming, Z., Morrow, A. L., Olsen, R. L., Otis, T. S., Parsons, L. H., Penland, S. N., Roberto, M., Siggins, G. R., Valenzuela, C. F., and Wallner, M. (2006). Basis of the GABAmimetic profile of ethanol. Alcohol. Clin. Exp. Res. 30, 731-744. 
Carta, M., Mameli, M., and Valenzuela, C. F. (2004). Alcohol enhances GABAergic transmission to cerebellar granule cells via an increase in Golgi cell excitability. J. Neurosci. 24, 3746-3751.

Concas, A., Mostallino, M. C., Perra, C., Lener, R., Roscetti, G., Barbaccia, M. L., Purdy, R. H., and Biggio, G. (1996). Functional correlation between allopregnanolone and [35S]-TBPS binding in the rat brain exposed to isoniazide, pentylenetetrazol or stress. Br. J. Pharmacol. 118, 839-846.

Conrad, K. L., Louderback, K. M., Gessner, C. P., and Winder, D. G. (2011). Stress-induced alterations in anxiety-like behavior and adaptations in plasticity in the bed nucleus of the stria terminalis. Physiol. Behav. 104, 248-256.

Costa, A. M., Spence, K. T., Smith, S. S., and ffrench-Mullen, J. M. (1995). Withdrawal from the endogenous steroid progesterone results in GABAA currents insensitive to benzodiazepine modulation in rat CA1 hippocampus. J. Neurophysiol. 74, 464-469.

Criswell, H. E., and Breese, G. R. (2005). A conceptualization of integrated actions of ethanol contributing to its GABAmimetic profile: a commentary. Neuropsychopharmacology 30, 1407-1425.

Ferdman, N., Murmu, R. P., Bock, J., Braun, K., and Leshem, M. (2007). Weaning age, social isolation, and gender interact to determine adult explorative and social behavior, and dendritic and spine morphology in prefrontal cortex of rats. Behav. Brain Res. 180, 174-182.

Finn, D. A., Beadles-Bohling, A. S., Beckley, E. H., Ford, M. M., Katherine, R., Gililland, K. R., Gorin-Meyer, R. E., and Wiren, K. M. (2006). A new look at the $5 \alpha$-reductase inhibitor finasteride. CNS Drug Rev. $12,53-76$.

Fone, K. C., and Porkess, M. V. (2008). Behavioural and neurochemical effects of post-weaning social isolation in rodents - relevance to developmental neuropsychiatric disorders. Neurosci. Biobehav. Rev. 32, 1087-1102.

Freeman, E. W., Purdy, R. H., Coutifaris, C., Rickels, K., and Paul, S. M. (1993). Anxiolytic metabolites of progesterone: correlation with mood and performance measures following oral progesterone administration to healthy female volunteers. Neuroendocrinology 58, 478-484.

Glykys, J., Peng, Z., Chandra, D., Homanics, G. E., Houser, C. R., and
Mody, I. (2007). A new naturally occurring GABAA receptor subunit partnership with high sensitivity to ethanol. Nat. Neurosci. 10, 40-48.

Hall, F. S., Huang, S., Fong, G. W., Pert, A., and Linnoia, M. (1998). Effect of isolation-rearing on voluntary consumption of ethanol, sucrose and saccharin in Fawn Hooded Wistar rats. Psychopharmacolgy (Berl.) 139, 210-216.

Hanchar, H. J., Wallner, M., and Olsen, R. W. (2004). Alcohol effects on gamma-aminobutyric acid type A receptors: are extrasynaptic receptors the answer? Life Sci. 76, 1-8.

Hu, Z. Y., Bourreau, E., Jung-Testas, I., Robel, P., and Baulieu, E. E. (1987). Neurosteroids: oligodendrocyte mitochondria convert cholesterol to pregnenolone. Proc. Natl. Acad. Sci. U.S.A. 84, 8215-8219.

Izumi, Y., Murayama, K., Tokuda, K., Covey, D. F., and Zorumski, C. F. (2007). GABAergic neurosteroids mediate the effects of ethanol on long-term potentiation in rat hippocampal slices. Eur. J. Neurosci. 26, 1881-1888.

Izumi, Y., Nagashima, K., Murayama, K., and Zorumski, C. F. (2005). Acute effects of ethanol on hippocampal long-term potentiation and longterm depression are mediated by different mechanisms. Neuroscience 136, 509-517.

Jia, F., Chandra, D., Homanics, G. E., and Harrison, N. L. (2008). Ethanol modulates synaptic and extrasynaptic GABAA receptors in the thalamus. J. Pharmacol. Exp. Ther. 326, 475-482.

Jia, F., Pignataro, L., and Harrison, N. L. (2007). GABAA receptors in the thalamus: $\alpha 4$ subunit expression and alcohol sensitivity. Alcohol 41, 177-185.

Kelm, M. K., Criswell, H. E., and Breese, G. R. (2011). Ethanol-enhanced GABA release: a focus on $\mathrm{G}$ proteincoupled receptors. Brain Res. Rev. 65, 113-123.

Kokate, T. G., Banks, M. K., Magee, T., Yamaguchi, S., and Rogawski, M. A. (1999). Finasteride, a $5 \alpha$-reductase inhibitor, blocks the anticonvulsant activity of progesterone in mice. $J$. Pharmacol. Exp. Ther. 288, 679-684.

Kumar, S., Porcu, P., Werner, D. F., Matthews, D. B., Diaz-Granados, J. L., Helfand, R. S., and Morrow, A. L. (2009). The role of GABAA receptors in the acute and chronic effects of ethanol: a decade of progress. Psychopharmacology (Berl.) 205, 529-564.

Lambert, J. J., Cooper, M. A., Simmons, R. D., Weir, C. J., and Belelli, D. (2009). Neurosteroids: endogenous allosteric modulators of GABAA receptors. Psychoneuroendocrinology 34(Suppl. 1), S48-S58.

Lu, L., Bao, G., Chen, H., Xia, P., Fan, X., Zhang, J., Pei, G., and Ma, L. (2003). Modification of hippocampal neurogenesis and neuroplasticity by social isolation. Exp. Neurol. 183 600-609.

Maguire, J., and Mody, I. (2008). GABAAR plasticity during pregnancy: relevance to postpartum depression. Neuron 59, 207-213.

Maguire, J. L., Stell, B. M., Rafizadeh, M., and Mody, I. (2005). Ovarian cyclelinked changes in GABAA receptors mediating tonic inhibition alter seizure susceptibility and anxiety. Nat. Neurosci. 8, 797-804.

Majewska, M. D., Harrison, N. L., Schwartz, R. D., Barker, J. L., and Paul, S. M. (1986). Steroid hormone metabolites are barbituratelike modulators of the GABA receptor. Science 232, 1004-1007.

Mathur, C., Prasad, V. V., Raju, V. S. Welch, M., and Lieberman, S. (1993). Steroids and their conjugates in the mammalian brain. Proc. Natl. Acad. Sci. U.S.A. 90, 85-88.

Matsumoto, K., Uzunova, V., Pinna, G. Taki, K., Uzunov, D. P., Watanabe, H., Mienville, J. M., Guidotti, A., and Costa, E. (1999). Permissive role of brain allopregnanolone content in the regulation of pentobarbitalinduced righting reflex loss. $\mathrm{Neu}$ ropharmacology 38, 955-963.

Mayford, M. (2007). Protein kinase signaling in synaptic plasticity and memory. Curr. Opin. Neurobiol. 17 313-317.

Moran, M. H., Goldberg, M., and Smith, S. S. (1998). Progesterone withdrawal II: insensitivity to the sedative effect of a benzodiazepine. Brain Res. 807, 91-100.

Morrisett, R. A., and Swartzwelder, H. S. (1993). Attenuation of hippocampal long-term potentiation by ethanol: a patch-clamp analysis of glutamatergic and GABAergic mechanisms. $J$. Neurosci. 13, 2264-2272.

Morrow, A. L., Janis, G. C., VanDoren, M. J., Matthews, D. B., Samson, H. H., Janak, P. H., and Grant, K. A. (1999). Neurosteroids mediate pharmacological effects of ethanol: a new mechanism of ethanol action? Alcohol. Clin. Exp. Res. 23, 1933-1940.

Morrow, A. L., Pace, J. R., Purdy, R. H., and Paul, S. M. (1990). Characterization of steroid interactions with gamma-aminobutyric acid receptor-gated chloride ion channels: evidence for multiple steroid recognition sites. Mol. Pharmacol. 37, 263-270.
Morrow, A. L., Suzdak, P. D., and Paul, S. M. (1987). Steroid hormone metabolites potentiate GABA receptor-mediated chloride ion flux with nanomolar potency. Eur. J. Pharmacol. 142, 483-485.

Morrow, A. L., VanDoren, M. J., Penland, S. N., and Matthews, D. B. (2001). The role of GABAergic neuroactive steroids in ethanol action, tolerance and dependence. Brain Res. Brain Res. Rev. 37, 98-109.

Moyer, J. R. Jr., Power, J. M., Thompson, L. T., and Disterhoft, J. F. (2000). Increased excitability of aged rabbit CA1 neurons after trace eyeblink conditioning. J. Neurosci. 20, 5476-5482.

Moyer, J. R. Jr., Thompson, L. T., and Disterhoft, J. F. (1996). Trace eyeblink conditioning increases CA1 excitability in a transient and learning-specific manner. J. Neurosci. 16, 5536-5546.

Paul, S. M., and Purdy, R. H. (1992). Neuroactive steroids. FASEB J. 6, 2311-2322.

Picazo, O., and Fernandez-Guasti, A. (1995). Anti-anxiety effects of progesterone and some of its reduced metabolites: an evaluation using the burying behavior test. Brain Res. 680 , 135-141.

Pietropaolo, S., Singer, P., Feldon, J., and Yee, B. K. (2008). The postweaning social isolation in C57BL/6 mice: preferential vulnerability in the male sex. Psychopharmacology (Berl.) 197, 613-628.

Purdy, R. H., Morrow, A. L., Moore, P. H. Jr., and Paul, S. M. (1991). Stress-induced elevations of $\gamma$ aminobutyric acid type A receptoractive steroids in the rat brain. Proc. Natl. Acad. Sci. U.S.A. 88, 4553-4557.

Quan, M. N., Tian, Y. T., Xu, K. H., Zhang, T., and Yang, Z. (2010). Post weaning social isolation influences spatial cognition, prefrontal cortical synaptic plasticity and hippocampal potassium ion channels in Wistar rats. Neuroscience 169, 214-222.

Reddy, D. S., Castaneda, D. C., O'Malley, B. W., and Rogawski, M. A. (2004). Anticonvulsant activity of progesterone and neurosteroids in progesterone receptor knockout mice. $J$. Pharmacol. Exp. Ther. 310, 230-239.

Roberto, M., Madamba, S. G., Moore, S. D., Tallent, M. K., and Siggins, G. R. (2003). Ethanol increases GABAergic transmission at both pre- and postsynaptic sites in rat central amygdala neurons. Proc. Natl. Acad. Sci. U.S.A. 100, 2053-2058. 
Roberts, L., and Greene, J. R. (2003). Post-weaning social isolation of rats leads to a diminution of LTP in the CA1 to subiculum pathway. Brain Res. 991, 271-273.

Rupprecht, R., and Holsboer, F. (1999). Neuroactive steroids: mechanisms of action and neuropsychopharmacological perspectives. Trends Neurosci. 22, 410-416.

Sanna, E., Mostallino, M. C., Murru, L., Carta, M., Talani, G., Zucca, S., Mura, M. L., Maciocco, E., and Biggio, G. (2009). Changes in expression and function of extrasynaptic GABAA receptors in the rat hippocampus during pregnancy and after delivery. J. Neurosci. 29, 1755-1765.

Sanna, E., Talani, G., Busonero, F., Pisu, M. G., Purdy, R. H., Serra, M., and Biggio, G. (2004). Brain steroidogenesis mediates ethanol modulation of GABAA receptor activity in rat hippocampus. J. Neurosci. 24, 6521-6530.

Sanna, E., Talani, G., Obili, N., Mascia, M. P., Mostallino, M. C., Secci, P. P., Pisu, M. G., Biggio, F., Utzeri, C., Olla, P., Biggio, G., and Follesa, P. (2011). Voluntary ethanol consumption induced by social isolation reverses the increase of GABAA receptor gene expression and function in the hippocampus of C57BL/6J mice. Front. Neurosci. 5:15. doi:10.3389/fnins.2011.00015

Santhakumar, V., Wallner, M., and Otis, T. S. (2007). Ethanol acts directly on extrasynaptic subtypes of GABAA receptors to increase tonic inhibition. Alcohol 41, 211-221.

Serra, M., Mostallino, M. C., Talani, G., Pisu, M. G., Carta, M., Mura, M. L.
Floris, I., Maciocco, E., Sanna, E., and Biggio, G. (2006). Social isolationinduced increase in alpha and delta subunit gene expression is associated with a greater efficacy of ethanol on steroidogenesis and GABA receptor function. J. Neurochem. 98, 122-133.

Serra, M., Pisu, M. G., Floris, I. and Biggio, G. (2005). Social isolation-induced changes in the hypothalamic-pituitaryadrenal axis in the rat. Stress 8, 259-264.

Serra, M., Pisu, M. G., Floris, I., Cara, V., Purdy, R. H., and Biggio, G. (2003). Social isolation-induced increase in the sensitivity of rats to the steroidogenic effect of ethanol. J. Neurochem. 85, 257-263.

Serra, M., Pisu, M. G., Littera, M., Papi, G., Sanna, E., Tuveri, F., Usala, L., Purdy, R. H., and Biggio, G. (2000). Social isolation-induced decreases in both the abundance of neuroactive steroids and GABAA receptor function in rat brain. J. Neurochem. 75, 732-740.

Sundstrom-Poromaa, I., Smith, D. H., Gong, Q. H., Sabado, T. N., Li, X., Light, A., Wiedmann, M., Williams, K., and Smith, S. S. (2002). Hormonally regulated $\alpha_{4} \beta_{2} \delta$ GABAA receptors are a target for alcohol. Nat. Neurosci. 5, 721-722.

Thompson, L. T., Moyer, J. R., and Disterhoft, J. F. (1996). Transient changes in excitability of rabbit CA3 neurons with a time course appropriate to support memory consolidation. J. Neurophysiol. 76, 1836-1849.

Tombaugh, G. C., Rowe, W. B. and Rose, G. M. (2005). The slow afterhyperpolarization in hippocampal CA1 neurons covaries with spatial learning ability in aged Fisher 344 rats. J. Neurosci. 25, 2609-2616.

Valzelli, L., Bernasconi, S., and Gomba, P. (1974). Effect of isolation on some behavioral characteristics in three strains of mice. Biol. Psychiatry 9, 329-334.

VanDoren, M. J., Matthews, D. B. Janis, G. C., Grobin, A. C., Devaud, L. L., and Morrow, A. L. (2000). Neuroactive steroid $3 \alpha$-hydroxy$5 \alpha$-pregnan-20-one modulates electrophysiological and behavioral actions of ethanol. J. Neurosci. 20, 1982-1989.

Voikar, V., Polus, A., Vasar, E., and Rauvala, H. (2005). Long-term individual housing in C57BL/6 J and DBA/2 mice: assessment of behavioral consequences. Genes Brain Behav. 4 240-252.

Wallner, M., Hanchar, H. J., and Olsen, R. W. (2003). Ethanol enhances $\alpha 4 \beta 3 \delta$ and $\alpha 6 \beta 3 \delta \gamma$-aminobutyric acid type A receptors at low concentrations known to affect humans. Proc. Natl. Acad. Sci. U.S.A. 100, 15218-15223.

Wei, W. Z., Faria, L. C., and Mody, I. (2004). Low ethanol concentrations selectively augment the tonic inhibition mediated by delta subunitcontaining GABAA receptors in hippocampal neurons. J. Neurosci. 24 8379-8382.

Weiner, J. L., and Valenzuela, C. F. (2006). Ethanol modulation of GABAergic transmission: the view from the slice. Pharmacol. Ther. 111 , 533-554.
Yin, H. H., Park, B. S., Adermark, L., and Lovinger, D. M. (2007). Ethanol reverses the direction of long-term synaptic plasticity in the dorsomedial striatum. Eur. J. Neurosci. 25, 3226-3232.

Zhu, P. J., and Lovinger, D. M. (2006). Ethanol potentiates GABAergic synaptic transmission in a postsynaptic neuron/synaptic bouton preparation from basolateral amygdala. J. Neurophysiol. 96, 433-441.

Conflict of Interest Statement: The authors declare that the research was conducted in the absence of any commercial or financial relationships that could be construed as a potential conflict of interest.

Received: 04 July 2011; paper pending published: 01 August 2011; accepted: 03 October 2011; published online: 21 October 2011.

Citation: Talani G, Biggio $G$ and Sanna E (2011) Enhanced sensitivity to ethanol-induced inhibition of LTP in CA1 pyramidal neurons of socially isolated C57BL/6J mice: role of neurosteroids. Front. Endocrin. 2:56. doi 10.3389/fendo.2011.00056

This article was submitted to Frontiers in Neuroendocrine Science, a specialty of Frontiers in Endocrinology.

Copyright (c) 2011 Talani, Biggio and Sanna. This is an open-access article subject to a non-exclusive license between the authors and Frontiers Media SA, which permits use, distribution and reproduction in other forums, provided the original authors and source are credited and other Frontiers conditions are complied with. 